\title{
Efficacy and Safety of Dabigatran vs. Warfarin in Patients With Atrial Fibrillation
}

\author{
- Sub-Analysis in Japanese Population in RE-LY Trial -
}

Masatsugu Hori, MD, PhD; Stuart J. Connolly, MD; Michael D. Ezekowitz, MD, PhD;

Paul A. Reilly, PhD; Salim Yusuf, MD, PhD;

Lars Wallentin, MD, PhD; the RE-LY Investigators

\begin{abstract}
Background: RE-LY (Randomized Evaluation of Long-term Anticoagulation Therapy) is an international multicenter study (18,113 patients from 967 centers in 44 countries) that demonstrated the ability of dabigatran to reduce the occurrence of both stroke and hemorrhage in patients who had atrial fibrillation (AF) with high risks of stroke compared with patients who received warfarin. From Japan, 326 patients were randomized in RE-LY.

Methods and Results: RE-LY was designed to compare 2 fixed doses (110 mg or $150 \mathrm{mg}$, twice daily) of dabigatran, each administered in a blinded manner, with open-label use of warfarin. There were no major differences in patient demographic information among the overall study population and Japanese patients. However, in Japanese patients, the proportion of prior stroke was higher but prior myocardial infarction was lower than in the overall. The yearly rate for the primary endpoints (stroke and systemic embolism) was 1.38, 0.67 and $2.65 \% /$ year for $110 \mathrm{mg}$ and $150 \mathrm{mg}$ dabigatran twice daily and warfarin, respectively. These results were similar to the overall results (1.54, 1.11 and $1.71 \%$ /year for each group, respectively). For any bleeding, the relative risk of dabigatran at $110 \mathrm{mg}$ and $150 \mathrm{mg}$ twice daily over warfarin was 0.79 and 1.06 , respectively, which was similar to the findings overall (dabigatran $110 \mathrm{mg}$ twice daily: $0.78 ; 150 \mathrm{mg}$ twice daily: 0.91 ).
\end{abstract}

Conclusions: In RE-LY, the efficacy and safety profiles of dabigatran for Japanese AF patients at high risk of stroke were essentially the same as for the study population overall. (Circ $J$ 2011; 75: 800-805)

Key Words: Atrial fibrillation; Bleeding; Dabigatran; Ischemic/hemorrhage stroke; Japanese cohort

A trial fibrillation (AF) is the most common sustained cardiac rhythm disturbance and its prevalence increases with age. Although AF occurs in less than $1 \%$ of individuals under 60 years of age, it occurs in more than $6 \%$ of those over the age of $80 .{ }^{1}$ Radiofrequency catheter ablation is widely performed as an effective treatment for recurrent, drug-resistant $\mathrm{AF}$, but several complications with an incidence of $3.9-6 \%$ have been reported. ${ }^{2}$

Most of the mortality and functional impairment associated with $\mathrm{AF}$ is due to the occurrence of ischemic stroke and systemic emboli. According to the Guidelines for Pharmacotherapy of Atrial Fibrillation (JCS 2008), warfarin is recommended for preventing stroke in AF patients with a $\mathrm{CHADS}_{2}$ score of 2 or more; however, for AF patients who have a $\mathrm{CHADS}_{2}$ score greater than 1, warfarin should be consid- ered. A recent meta-analysis by Hart et al, which included 6 clinical trials encompassing 2,900 participants (AFASAK I, SPAF I, BAATAF, CAFA, SPINAF, EAFT), found that when compared with the control group, adjusted-dose warfarin reduced stroke by $64 \%(49-74 \%) .{ }^{3}$ In another meta-analysis, the incidence of both major and minor bleeding in warfarin was significantly higher than placebo or reference drugs (major bleeding: $\mathrm{P}=0.01$, minor bleeding: $\mathrm{P}<0.001) .{ }^{4}$ From the clinical perspective also, warfarin is cumbersome to use because of its slow onset of action (and offset of action) and the high inter- and intra-individual variability in reaching effective plasma concentrations. Warfarin is also known to interact with foods and other drugs, and because of its narrow therapeutic window, frequent laboratory monitoring of antithrombotic activity in individual patients is required. Thus,

Received February 16, 2011; accepted March 1, 2011; released online March 19, 2011 Time for primary review: 5 days

Osaka Medical Center for Cancer and Cardiovascular Diseases, Osaka (M.H.), Japan; Population Health Research Institute, McMaster University and Hamilton Health Sciences, Hamilton, ON (S.J.C., S.Y.), Canada; Lankenau Institute for Medical Research and the Heart Center, Wynnewood, PA (M.D.E.), USA; Boehringer Ingelheim Pharmaceuticals Inc, Ridgefield, CT (P.A.R.), USA; and Uppsala Clinical Research Center, Uppsala (L.W.), Sweden

Mailing address: Masatsugu Hori, MD, PhD, Osaka Medical Center for Cancer and Cardiovascular Diseases, 1-3-3 Nakamichi, Higashinari-ku, Osaka, 537-8511, Japan. E-mail: hori-ma@mc.pref.osaka.jp

ISSN-1346-9843 doi:10.1253/circj.CJ-11-0191

All rights are reserved to the Japanese Circulation Society. For permissions, please e-mail: cj@j-circ.or.jp 
new anticoagulant agents that are effective, safe and convenient to use are eagerly awaited for use in clinical practice.

Dabigatran etexilate is an oral prodrug and rapidly converted by a serum esterase to dabigatran, which has potent antithrombotic effects and acts by specifically and directly blocking the activity of thrombin (both free and clot-bound), the central enzyme responsible for clot (thrombus) formation. The drug profile of dabigatran is that it has a rapid onset and offset (half life of 12-17 h), predictable and consistent anticoagulant effects, low potential for drug-drug interactions, no drug-food interactions and no requirement for routine coagulation monitoring. ${ }^{5}$

RE-LY (Randomized Evaluation of Long-term Anticoagulation Therapy) is an international, multicenter, blinded study designed to compare 2 doses of dabigatran with warfarin for the prevention of stroke and systemic embolism (SEE) in patients with AF. ${ }^{6,7}$ A total of 18,113 AF patients with a high risk of stroke were randomly assigned, in a blinded manner, to receive fixed doses of dabigatran or, in an unblended manner, to receive adjusted-dose warfarin. Patients were recruited from 951 clinical centers in 44 countries. The results demonstrate that compared with warfarin, $150 \mathrm{mg}$ of dabigatran twice daily reduced both stroke and intracranial and life-threatening bleeding without any significant difference in overall major bleeding. In comparison, $110 \mathrm{mg}$ dabigatran twice daily had a similar effect at reducing the risk of stroke, but was found to reduce intracranial, life-threatening and major bleeding. In Japan, 326 patients were randomized into RE-LY and this report describes the core results of the RE-LY study in the Japanese cohort, compared with the overall RE-LY population.

\section{Methods}

\section{Trial Design}

The RE-LY trial was designed according Prospective, Randomized, Open, Blinded-Endpoint (PROBE), a clinical trial design method. In the RE-LY study, 2 fixed doses of dabigatran, each administered in a blinded manner, were compared with open-label use of warfarin in patients who had AF and were at increased risk of stroke.

To decrease evaluation bias, the following measures were included in the study design: (1) the database and data handling were assigned to an academic group independent from the sponsor, (2) we reported objective, clinically relevant outcomes, (3) the authors were blinded to the dabigatran doses, and (4) there were blinded Adjudication Committee(s). The details of the design of this study have been described previously. ${ }^{8}$ The study was funded by Boehringer Ingelheim and coordinated by the Population Health Research Institute (Hamilton, ON, Canada), which independently managed the database and performed the primary data analyses. An operations committee, with assistance from an international steering committee and with participation by the sponsor, was responsible for the design, conduct and reporting of the study.

\section{Study Participants}

Patients were included in the study if they had documented $\mathrm{AF}$ and at least one of the following risk factor for stroke: previous ischemic stroke, transient ischemic attack [TIA] or SEE; left ventricular dysfunction; age $\geq 75$ years (or were aged between 65 and 74 years and had a history of diabetes mellitus, coronary artery disease [CAD], or hypertension). Patients were excluded if they had a severe heart-valve dis- order, stroke within the last 14 days or severe stroke within 6 months of the screening, any condition that increased the risk of hemorrhage, a creatinine clearance $<30 \mathrm{ml} / \mathrm{min}$, active liver disease or pregnancy.

\section{Procedure}

All trial participants were randomly assigned to either receive 1 of the 2 doses of dabigatran, or to receive warfarin. Dabigatran was administered, in a blinded manner, in capsules containing either $110 \mathrm{mg}$ (DE110) or $150 \mathrm{mg}$ (DE150) of the drug, to be taken twice daily. Warfarin was administered unblinded, and was adjusted locally to an international normalized ratio (INR) of 2.0-3.0 (INR of 2.0-2.6 for Japanese patients aged $\geq 70$ years).

\section{Endpoints}

The primary efficacy endpoint was the occurrence of stroke (including hemorrhagic) and SEE. The stroke was categorized as ischemic or hemorrhagic or unspecified (based on CT or magnetic resonance scanning or autopsy). SEE was defined as an acute vascular occlusion of the extremities or any organ (kidneys, mesenteric arteries, spleen, retina or grafts).

Safety endpoints were bleeding events (major and minor), hepatic dysfunction and other adverse events (AE). Major bleeding was defined as a reduction in the hemoglobin level of at least $20 \mathrm{~g} / \mathrm{L}$, transfusion of at least 2 units (4.5 in Japanese unit) of blood, or symptomatic bleeding in a critical area or organ. Life-threatening bleeding was a subcategory of major bleeding that consisted of fatal bleeding, symptomatic intracranial hemorrhage $(\mathrm{ICH})$, bleeding with a decrease in the hemoglobin level of at least $50 \mathrm{~g} / \mathrm{L}$, or bleeding requiring transfusion of at least 4 units (9.0 in Japanese unit) of blood or inotropic agents or bleeding which necessitated surgery. All other bleeding was considered minor.

\section{Pharmacokinetics (PKs)}

The PK parameters to be analyzed were as follows: (1) the pre-dose plasma concentrations at steady state (Cpre,ss) and (2) the plasma concentration $2 \mathrm{~h}$ after drug administration at steady state (C2,ss; approximate maximum plasma concentration).

\section{Statistical Analysis}

The primary analysis in this subgroup analysis was designed to compare the yearly rate of the primary endpoint events for either dose of dabigatran with that for warfarin, as evaluated by Cox proportional-hazards modeling (the hazard ratio and 95\% confidence interval). The primary endpoint was assessed by the time to the first occurrence of stroke or SEE and evaluated in the randomized set, which included all randomized subjects in the treatment groups, regardless of whether the subjects took the study medication or not. The AE were evaluated in the safety analysis set, which included all randomized subjects who had taken at least one dose of study medication.

\section{Results}

\section{Characteristics of the Study Patients}

Geographic Regions The 18,113 randomized patients were equally distributed across the 3 treatment groups, with 6,015 randomized to DE110, 6,076 to DE150 and 6,022 to warfarin. Approximately $36 \%$ of the patients were from the United States or Canada, 26\% were from Western Europe, $12 \%$ were from Central Europe, approximately $15 \%$ of the 


\begin{tabular}{|c|c|c|}
\hline Characteristic & Overall & Japanese \\
\hline Randomized & 18,113 & 326 \\
\hline Mean age (years) & 71.5 & 71.2 \\
\hline Male (\%) & 63.6 & 76.7 \\
\hline \multicolumn{3}{|l|}{$\mathrm{CHADS}_{2}$ score } \\
\hline Mean & 2.1 & 2.2 \\
\hline $0-1(\%)$ & 31.9 & 31.3 \\
\hline $2(\%)$ & 35.6 & 34.0 \\
\hline $3+(\%)$ & 32.5 & 34.7 \\
\hline Prior stroke/SEE/TIA (\%) & 21.8 & 33.1 \\
\hline Prior Ml (\%) & 16.6 & 5.5 \\
\hline CHF (\%) & 32.0 & 31.0 \\
\hline Baseline ASA (\%) & 39.8 & 35.9 \\
\hline VKA naïve (\%) & 50.4 & 56.1 \\
\hline
\end{tabular}

RE-LY, Randomized Evaluation of Long-term Anticoagulation Therapy; SEE, systemic embolism; TIA, transient ischemic event; $\mathrm{MI}$, myocardial infarction; CHF, congestive heart failure; VKA, vitamin $\mathrm{K}$ antagonist.

patients were from Asia, 5\% were from Latin America, and $6 \%$ were from other regions.

\section{Follow-up}

In Japan, RE-LY was conducted from March 2007 to March 2009. In the Japanese cohort, 326 patients were randomized from 49 clinical sites. The total period in which patients were exposed to the test drugs was 1.3 years (median). The time ratios, for patients with an INR $<2.0,2.0-3.0$ and $>3.0$ for warfarin, were $36.8 \%, 57.6 \%$ and $5.6 \%$, respectively whereas in the overall study population, they were $22.2 \%, 64.4 \%$ and $13.5 \%$, respectively. Thus Japanese patients tended to have lower INRs that the rest of the global study.

\section{Demographic Information}

There were no major differences between the overall study population and Japanese patients with respect to baseline demographic data and disease characteristic information (Table 1). However, in the Japanese cohort, the proportion $(33.1 \%)$ of prior stroke/SEE/TIA was higher but prior myocardial infarction (MI) was lower (5.5\%) than in the overall study group (21.8\% and $16.6 \%$, respectively).

\section{Efficacy}

The primary outcome measured was stroke/SEE. In the Japanese patients, a total of 7 stroke/SEEs occurred during the trial: 2 in the DE110 group, 1 in the DE150 group and 4 in the warfarin group (Table 2). The yearly rates for stroke/SEE were 1.38, 0.67 and 2.65\%/year in the DE110, DE150, and warfarin groups, respectively, and were comparable with the yearly rates for stroke/SEE in the overall study population $(1.54,1.11$, and $1.71 \%$ /year in the DE110, DE150 and warfarin groups, respectively). No SEEs occurred in the dabigatran groups (Table 2). The relative risk (RR) for stroke/SEE with DE110 and DE150 over warfarin in the Japanese patient population was 0.52 and 0.25 , respectively.

In the overall study population, both doses of dabigatran were non-inferior to warfarin $(\mathrm{P}<0.001)$ but $\mathrm{DE} 150$ was superior to warfarin $(\mathrm{P}<0.001)$ for the primary efficacy endpoint (stroke/SEE). The RR for stroke/SEE using DE110 and DE150 was 0.90 and 0.65 , respectively.

In the Japanese patients, MI did not occur during the trial in any of the groups.

\section{Safety/Bleeding}

Among the Japanese patients, there were 18 major bleeding events: 8 for the DE110 group, 5 for the DE150 group and 5 for the warfarin group (yearly rate: DE110, 5.53\%/year; DE150, 3.33\%/year; warfarin, 3.31\%/year) (Table 3). At both doses of dabigatran, there were no significant differences compared with the warfarin group. These results are not statis-

\begin{tabular}{|lccc|}
\hline \multirow{3}{*}{ Table 2. Efficacy Endpoints: Stroke or Systemic Embolism in Japanese Subjects } \\
\cline { 2 - 4 } & \multicolumn{3}{c|}{ Number (rate/year) } \\
\cline { 2 - 4 } & $\mathbf{D E 1 1 0}(\mathbf{n}=107)$ & $\mathbf{D E 1 5 0}(\mathbf{n}=111)$ & Warfarin $(\mathbf{n}=108)$ \\
Stroke or systemic embolism & $2(1.38) /(1.54)^{*}$ & $1(0.67) /(1.11)^{*}$ & $4(2.65) /(1.71)^{\star}$ \\
Stroke & $2(1.38)$ & $1(0.67)$ & $3(1.99)$ \\
Ischemic stroke & $2(1.38)$ & $0(0.0)$ & $2(1.33)$ \\
Hemorrhagic stroke & $0(0.0)$ & $1(0.67)$ & $1(0.66)$ \\
Systemic embolism & $0(0.0)$ & $0(0.0)$ & $2(1.33)$ \\
\hline
\end{tabular}

${ }^{*}$ Rate/year data from the overall Randomized Evaluation of Long-term Anticoagulation Therapy (RE-LY) study population.

\begin{tabular}{|c|c|c|c|}
\hline & \multicolumn{3}{|c|}{ Number (rate/year) } \\
\hline & DE110 $(n=107)$ & $\operatorname{DE} 150(n=111)$ & Warfarin $(n=108)$ \\
\hline Major bleeding & $8(5.53) /(2.87)^{*}$ & $5(3.33) /(3.32)^{*}$ & $5(3.31) /(3.57)^{\star}$ \\
\hline Life threatening & $1(0.69)$ & $3(2.00)$ & $2(1.33)$ \\
\hline Gastrointestinal & $3(2.11)$ & $1(0.67)$ & $1(0.67)$ \\
\hline Intracranial & $1(0.69)$ & $1(0.67)$ & $1(0.66)$ \\
\hline Minor bleeding & $35(24.19) /(13.16)^{*}$ & $50(33.26) /(14.85)^{\star}$ & $50(33.14) /(16.37)^{\star}$ \\
\hline Any bleeding (major or minor) & $40(27.64) /(14.74)^{*}$ & $52(34.59) /(16.56)^{*}$ & $51(33.81) /(18.37)^{\star}$ \\
\hline
\end{tabular}

${ }^{*}$ Rate/year data from the overall Randomized Evaluation of Long-term Anticoagulation Therapy (RE-LY) study population. 
tically heterogeneous compared with the overall study results. Regarding the gastrointestinal major bleeding, the yearly rate for the DE110, DE150 and warfarin groups of Japanese patients was $2.11,0.67$ and 0.67 , respectively. There was no discontinuation of drug therapy due to major bleeding.

For minor bleeding, the yearly rate for the DE110, DE150 and warfarin groups of Japanese patients was 24.19, 33.26 and $33.14 \%$ /year $(13.16,14.85$ and $16.37 \%$ /year in the overall population, respectively). For any bleeding, the RR of DE110 and DE150 over warfarin was 0.79 and 1.06 , respectively, and these patterns were similar to those in the overall study population (DE110, 0.78; DE150, 0.91).

\section{Adverse Events and Liver Function}

In this study, for the Japanese population dyspepsia was the most common AE during treatment with dabigatran, which was same as in the overall study population. Dyspepsia, defined to include the coding terms upper abdominal pain, abdominal pain, abdominal discomfort, epigastric discomfort and dyspepsia, occurred in 11 patients $(10.2 \%)$ in the warfarin group, and in $23(21.7 \%)$ and 30 patients $(27.3 \%)$ in the DE1 10 and DE150 groups, respectively (Table 4). The discontinuation rates attributed to dyspepsia in the Japanese patients were $0.9 \%(1 / 106), 4.5 \%(5 / 110)$ and $0 \%(0 / 108)$ in the DE110, DE150 and warfarin groups, respectively (as the $\mathrm{AE}$ in the safety set). Elevated serum aspartate aminotransferase or alanine aminotransferase levels of more than 3-fold the upper limit of the normal range did not occur more frequently with dabigatran (at either dose) than with warfarin.

\begin{tabular}{|c|c|c|c|}
\hline $\begin{array}{c}\text { AE occurring } \\
\text { in } \geq 5 \% \\
\text { of any group }\end{array}$ & $\begin{array}{c}D E 110 \\
(n=106)\end{array}$ & $\begin{array}{c}D E 150 \\
(n=110)\end{array}$ & $\begin{array}{c}\text { Warfarin } \\
(n=108)\end{array}$ \\
\hline Dyspepsia* & $23(21.7)$ & 30 (27.3) & $11(10.2)$ \\
\hline Nasopharyngitis & $48(45.3)$ & $56(50.9)$ & $53(49.1)$ \\
\hline Back pain & $11(10.4)$ & 19 (17.3) & $14(13.0)$ \\
\hline Diarrhea & $3(2.8)$ & 15 (13.6) & $6(5.6)$ \\
\hline Eczema & $7(6.6)$ & $6(5.5)$ & $10(9.3)$ \\
\hline Arthralgia & $6(5.7)$ & $10(9.1)$ & $7(6.5)$ \\
\hline Constipation & $5(4.7)$ & $4(3.6)$ & 9 (8.3) \\
\hline Periodontitis & $5(4.7)$ & $2(1.8)$ & $9(8.3)$ \\
\hline Contusion & $5(4.7)$ & $9(8.2)$ & $3(2.8)$ \\
\hline Hypertension & $8(7.5)$ & $4(3.6)$ & $7(6.5)$ \\
\hline Headache & $6(5.7)$ & $5(4.5)$ & $8(7.4)$ \\
\hline Chest pain & $5(4.7)$ & $8(7.3)$ & $3(2.8)$ \\
\hline Cataract & $4(3.8)$ & $5(4.5)$ & $7(6.5)$ \\
\hline Reflux esophagitis & $6(5.7)$ & $1(0.9)$ & $1(0.9)$ \\
\hline Peripheral edema & $5(4.7)$ & $4(3.6)$ & $6(5.6)$ \\
\hline Vomiting & $2(1.9)$ & $6(5.5)$ & $5(4.6)$ \\
\hline Rash & $3(2.8)$ & $6(5.5)$ & $2(1.9)$ \\
\hline Any adverse events & $102(96.2)$ & $103(93.6)$ & $101(93.5)$ \\
\hline
\end{tabular}

*Dyspepsia was defined as including the coding terms upper abdominal pain, abdominal pain, abdominal discomfort, epigastric discomfort and dyspepsia.

\section{PKs}

At the trough (Cpre,ss) and $2 \mathrm{~h}(\mathrm{C} 2, \mathrm{ss})$ after administration,

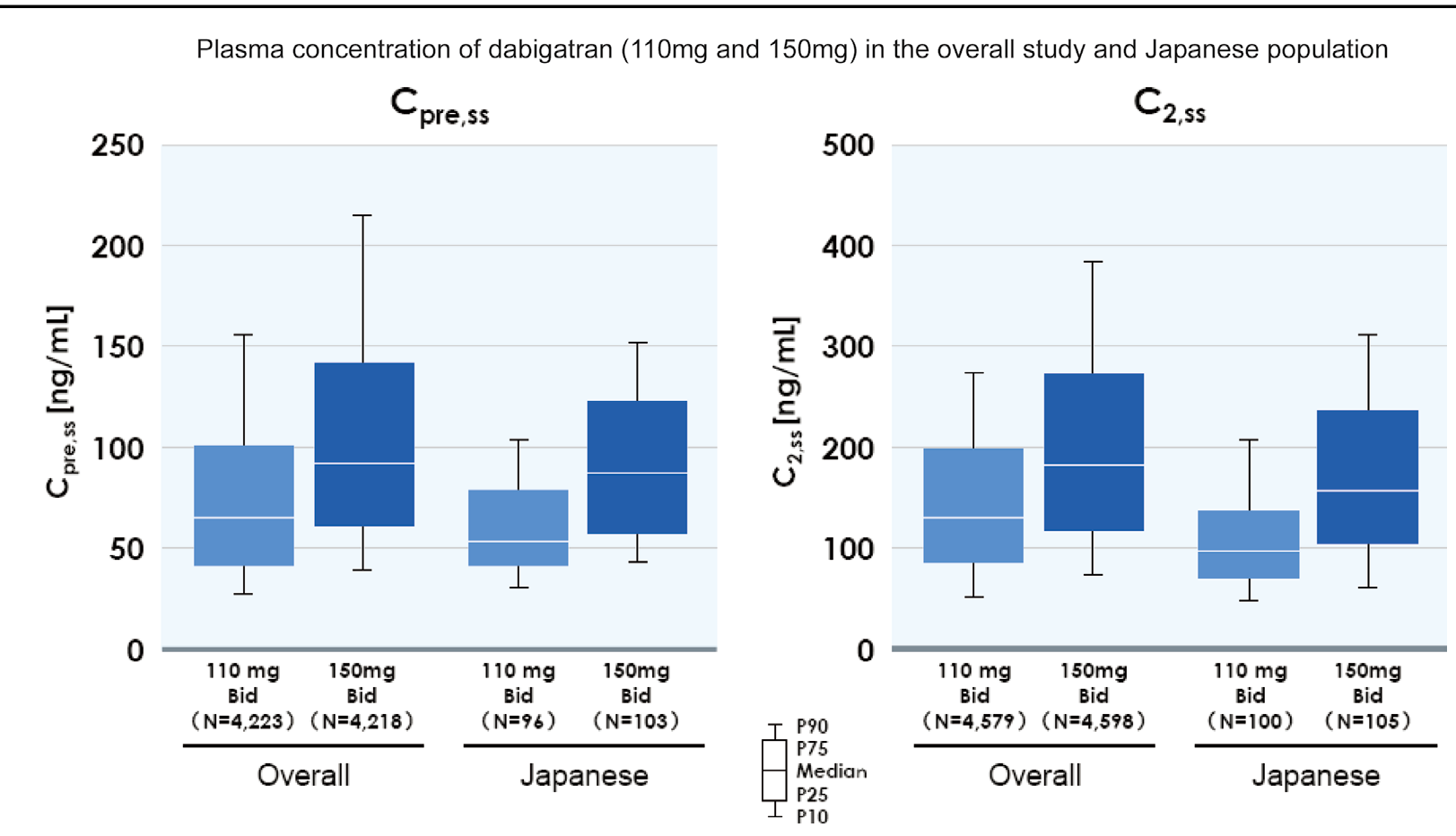

Figure. Plasma concentrations of dabigatran at the trough and $2 \mathrm{~h}$ after administration. Cpre,ss is the pre-dose plasma concentration at steady state; C2,ss is the plasma concentration at $2 \mathrm{~h}$ after drug administration at steady state (approximate maximum plasma concentration). 
there were no differences in the plasma concentration of dabigatran in the overall study population compared with the Japanese population (Figure).

\section{Discussion}

In RE-LY, recruitment was widespread and included countries where anticoagulants are commonly used as well as countries where they are not. The bulk of recruitment occurred in Western Europe and the United States/Canada (62\%), where vitamin $\mathrm{K}$ antagonist (VKA) use is widespread, but Asia was also well represented (15\% of patients) as was central Europe $(12 \%)$. Thus, the results are representative of a wide range of countries with varying medical practices.

From Japan, 326 AF patients were randomized in RE-LY. In general, there were no major differences among the overall study population and the Japanese patients with respect to demographic information. However, in the Japanese patients, the percentage of prior stroke/SEE/TIA was higher but prior MI was lower than for the overall study population. The CHADS2 in Japanese patients (mean 2.2) was comparable with the overall study population (mean 2.1 ), which suggests that Japanese patients have comparable cerebrovascular risk. The time in the therapeutic range, during which each patient had an INR $<2.0$ was higher in the Japanese patients $(36.8 \%)$ than in the overall study population $(22.2 \%)$, which reflects a tendency in Asian countries to use warfarin at a lower level of intensity than in other parts of the world due to fears of a higher incidence of ICH.

Yasaka et al reported that major ischemic or hemorrhagic events often occur in elderly Japanese patients with non-valvular AF (NVAF), and therefore an INR between 1.6 and 2.6 has been generally considered as optimal for elderly patients $\geq 70$ years old to prevent such events, ${ }^{9}$ as documented in the Guidelines for Pharmacotherapy of Atrial Fibrillation (JCS 2008). Therefore, in the RE-LY trial the target INR was set at 2.0-2.6 for Japanese patients aged $\geq 70$ years who were randomized to the warfarin group, to ensure safety while at the same time remaining consistent with the overall targets of the study to maintain INR between 2.0 and 3.0. Such a strategy was expected to lead to benefit without undue risk of bleeds.

The yearly rates of dabigatran for stroke/SEE (DE110, 1.38; DE150, 0.67; warfarin, 2.65\%/year) in the Japanese patients were comparable with those for the larger RE-LY population (DE110, 1.54; DE150, 1.11; warfarin, 1.71\%/year). The RR for stroke/SEE in the DE110 and DE150 groups over the warfarin group of Japanese patients was 0.52 (relative risk reduction $[R R R]=48 \%)$ and $0.25(R R R=75 \%)$, respectively, though each had wide confidence intervals.

In the overall study population, the RRR for stroke/SEE using DE110 and DE150, compared with warfarin, was $10 \%$ and $35 \%$, respectively. Both dabigatran doses were non-inferior to warfarin in reducing the occurrence of stroke/SEE. However, the risk reduction by DE150 was significantly superior to that of warfarin $(\mathrm{P}<0.001)$. The finding that dabigatran was superior over warfarin is notable in view of warfarin's large effect vs. placebo and the results of recent trials. Warfarin reduces stroke by $64 \%$ compared with placebo or reference drugs. ${ }^{3}$ For ischemic stroke and unspecified stroke, the reduction by DE150 of a further $24 \%$ RRR, compared with warfarin was significant $(\mathrm{P}=0.03)$ and is indeed impressive and indicates that it is possible to improve even on a very effective therapy such as warfarin while maintaining relative safety. Hemorrhagic stroke decreased by two-thirds compared with warfarin for both doses (RR over warfarin: DE110, 0.31, P<
0.001; DE150, 0.26, $\mathrm{P}<0.001)$. This result is very important because the yearly rate of hemorrhagic stroke for VKA is higher than for aspirin in NVAF patients (VKA, 0.5\%/year; aspirin, $0.3 \%$ /year; the RR of VKA compared with aspirin: 1.84 (0.87-3.87), $\mathrm{P}=0.19) .^{10}$

For the plasma concentrations of dabigatran at the trough and $2 \mathrm{~h}$ after administration, there were no differences in the PK profile between the overall study population and the Japanese population. Thus, the efficacy profile of dabigatran over warfarin in Japanese patients is basically consistent with the overall study population.

The primary safety endpoint for this trial was bleeding. In the Japanese patients, a total of 18 major bleeds occurred during the trial: 8, 5 and 5 events in the DE110, DE150, and warfarin groups, respectively (yearly rate: DE110, 5.53; DE150, 3.33; warfarin, 3.31\%). On the other hand, the rate of major bleeding was $3.57 \% / y e a r$ in the warfarin group, as compared with $2.87 \%$ /year in the DE110 group (RR 0.80; $95 \%$ CI $0.70-0.93 ; \mathrm{P}=0.003)$ and $3.32 \% / y e a r e a r$ in the DE150 group (RR 0.93; 95\% CI, 0.81-1.07; $\mathrm{P}=0.32$ ). The incidence of major bleeding was dose-related in the dabigatran group and significantly reduced when using DE110 compared with warfarin in the overall study, but this was not apparent in the Japanese population, most likely due to the limited number of events. The major bleeding events in the Japanese patients included those that occurred several days after the discontinuation of the test drugs or were considered as being due to underlying diseases such as colon polyp (DE110, 5; DE150, 2; warfarin, 2 events). In the overall study population, major bleeding was significantly reduced using DE110 compared with warfarin. Thus, it is unlikely that major bleeding with DE110 is particularly higher in Japanese patients.

The occurrence of minor bleeds in all groups of Japanese patients was higher than in the overall study population. It should be noted, however, that they were reported by the investigators but not adjudicated. However, the reasons for the higher occurrence of minor bleeding in Japanese patients are still not clear.

The most devastating complication of warfarin therapy is ICH. It has been reported in RE-LY that the rate of this complication with both doses of dabigatran was significantly less than one-third of the rate observed with warfarin, suggesting an important advantage of dabigatran over warfarin. In the Japanese cohort, the rates of ICH in the RE-LY trial were very low in each group: 1, 1 and 1 in DE110, DE150 and warfarin groups, respectively. Due to a relatively modest number of Japanese patients, a clear difference between dabigatran and warfarin was not detected but was found to be consistent with the overall study population. Aguilar et al reported that the incidence of ICH with VKA was higher than with antiplatelets (odds ratio of VKA compared with antiplatelets: 1.98 (1.20-3.28). ${ }^{11}$ Additionally, Shen et al reported that Asian patients are at a greater risk for ICH than Caucasian patients. ${ }^{12}$ Thus, the reduction of $\mathrm{ICH}$ would be very important for Japanese AF patients with a high stroke risk.

The only AE that was significantly more common with dabigatran than with warfarin was dyspepsia. Dyspepsia was defined as composite of upper abdominal pain, abdominal pain, abdominal discomfort, epigastric discomfort and dyspepsia, all of which have dyspepsia-like symptoms. Dabigatran is not well-absorbed, thus one could infer a local effect, but this is purely speculative. Proton pump inhibitors might be effective for relieving the dyspepsia during dabigatran treatment. Veldhuyzen et al reported that treatment with omeprazole provides superior symptom relief compared 
with ranitidine, cisapride or placebo in the treatment of Helicobacter pylori-negative primary care dyspepsia patients in the CADET-HN Study. ${ }^{13}$ Ximelagatran, an earlier direct thrombin inhibitor (DTI), was found to be hepatotoxic. ${ }^{14}$ In Japanese patients, we did not find evidence of hepatotoxicity with dabigatran, which suggests that hepatotoxicity is not a broad effect of DTIs.

In conclusion, the efficacy and safety profiles of dabigatran for Japanese AF patients at high risk for stroke AF are comparable with the overall RE-LY study population. These data further support the findings of the broader RE-LY trial that dabigatran has potential clinical utility as an antithrombotic agent in patients with AF.

\section{Acknowledgments}

We would especially like to thank the following investigators who participated in RE-LY in Japan: Aihara N, Aoyagi T, Arai H, Arita Y, Ebisawa S, Eguma H, Fujii K, Fujii S, Fujimori K, Fujita M, Fukuchi M, Fukuizumi H, Fukunami M, Fukuyama K, Furukawa Y, Furuya J, Gomyo Y, Goto S, Haneda K, Hara M, Hara S, Hasegawa T, Hashimoto A, Higashikata T, Hirata N, Hiroe M, Hishida E, Hiyoshi Y, Hori M, Iesaka Y, Igarashi K, Igarashi T, Iijima T, Ikedou H, Inou T, Inoue H, Inoue $\mathrm{M}$, Ishibashi $\mathrm{Y}$, Ishii $\mathrm{K}$, Ishimaru S, Ito N, Iwade $\mathrm{K}$, Iwasaki J, Kajiya T, Kakinoki S, Kamakura S, Kamijo M, Kaneda T, Kasai Y, Kasanuki H, Kataoka C, Katayama M, Katayama Y, Kato H, Kawasaki M, Kihara Y, Kikuchi S, Kimura K, Kishi K, Kitajima H, Kobayakawa N, Kobayashi H, Kobayashi S, Kono K, Koretsune Y, Kurita T, Lee Y, Marui N, Maruyama I, Matsubara N, Matsuo Y, Matsuyama T, Mawatari E, Meno H, Minoshima A, Miyamoto N, Mizuno H, Mizutani K, Morikawa S, Morimoto S, Myojin K, Nagai H, Nagai K, Nagao T, Nagaoka H, Nagata Y, Nakagawa S, Nakamura D, Nakamura T, Nakao M, Nakatani S, Nishi Y, Nishina N, Nukata M, Obana M, Oda T, Ogawa S, Ogawa T, Ogiwara F, Ohi K, Ohsawa K, Ohtani Y, Okajima K, Okazaki O, Okazaki Y, Onaka H, Otsuka K, Sakakibara T, Sakurai S, Sasaki Y, Sato H, Seki T, Shimizu N, Shimizu Y, Shinohe R, Shiraki T, Shoji Y, Shutta R, Sugaya T, Sugii M, Sugito Y, Sugiyama E, Sumii K, Susuki T, Suzuki C, Suzuki H, Suzuki S, Takagi C, Takagi M, Takagi M, Takahashi W, Takama N, Takenaka T, Takeuchi K, Takeuchi K, Takizawa M, Tanabe K, Tanaka K, Tanaka N, Tanaka N, Tanaka S, Taniike M, Tanouchi J, Toyoshima Y, Tsuda Y, Tsukioka D, Uchida T, Uchiyama S, Ueda K, Ueyama Y, Ujihira T, Uozumi H, Usui M, Watabe $H$, Yagi M, Yamada T, Yamagami K, Yamagishi T, Yamaguchi $H$, Yamaguchi K, Yamaguchi T, Yamamoto H, Yamauchi H, Yasaka M, Yokochi M, Yokoi K, Zen E.

\section{References}

1. Fuster V, Rydén LE, Asinger RW, Cannom DS, Crijns HJ, Frye RL, et al. ACC/AHA/ESC guidelines for the management of patients with atrial fibrillation: Executive summary: A report of the Ameri- can College of Cardiology/American Heart Association Task Force on Practice Guidelines and the European Society of Cardiology Committee for Practice Guidelines and Policy Conferences (Committee to Develop Guidelines for the Management of Patients with Atrial Fibrillation). Circulation 2001; 104: 2118-2150.

2. Takahashi A, Kuwahara T, Takahashi Y. Complications in the catheter ablation of atrial fibrillation: Incidence and management. Circ J 2009; 73: 221-226.

3. Hart RG, Pearce LA, Aguilar MI. Meta-analysis: Antithrombotic therapy to prevent stroke in patients who have non-valvular atrial fibrillation. Ann Intern Med 2007; 146: 857-867.

4. Lip GY, Edwards SJ. Stroke prevention with aspirin, warfarin and ximelagatran in patients with non-valvular atrial fibrillation: A systematic review and meta-analysis. Thromb Res 2006; 118: $321-$ 333.

5. Stangier J. Clinical pharmacokinetics and pharmacodynamics of the oral direct thrombin inhibitor dabigatran etexilate. Clin Pharmacokinet 2008; 47: 285-295.

6. Connolly SJ, Ezekowitz MD, Yusuf S, Eikelboom J, Oldgren J, Parekh A, et al. Dabigatran versus warfarin in patients with atrial fibrillation. N Engl J Med 2009; 361: 1139-1151.

7. Connolly SJ, Ezekowitz MD, Yusuf S, Reilly PA, Wallentin L, Newly identified events in the RE-LY trial. N Engl J Med 2010; 363: $1875-1877$.

8. Ezekowitz MD, Connolly SJ, Parekh A, Reilly PA, Varrone J, Wang $\mathrm{S}$, et al. Rationale and design of RE-LY: Randomized evaluation of long-term anticoagulant therapy, warfarin, compared with dabigatran. Am Heart J 2009; 157: 805-810.

9. Yasaka M, Minematsu K, Yamaguchi T. Optimal intensity of international normalized ratio in warfarin therapy for secondary prevention of stroke in patients with non-valvular atrial fibrillation. Intern Med 2001; 40: 1183-1188.

10. van Walraven C, Hart RG, Singer DE, Laupacis A, Connolly S, Petersen $\mathrm{P}$, et al. Oral anticoagulants vs aspirin in nonvalvular atrial fibrillation an individual patient meta-analysis. JAMA 2002; 288: $2441-2448$.

11. Aguilar MI, Hart R, Pearce LA. Oral anticoagulants versus antiplatelet therapy for preventing stroke in patients with non-valvular atrial fibrillation and no history of stroke or transient ischemic attacks. Cochrane Database Syst Rev 2007; 3: CD006186.

12. Shen AY, Yao JF, Brar SS, Jorgensen MB, Chen W. Racial/ethnic differences in the risk of Intracranial hemorrhage among patients with atrial fibrillation. J Am Coll Cardiol 2007; 50: 309-315.

13. Veldhuyzen van Zanten SJ, Chiba N, Armstrong D, Barkun A, Thomson A, Smyth S, et al. Randomized trial comparing omeprazole, ranitidine, cisapride, or placebo in helicobacter pylori negative, primary care patients with dyspepsia: The CADET-HN Study. Am J Gastroenterol 2005; 100: 1477-1488.

14. Diener HC; Executive Steering Committee of the SPORTIFF III and $\mathrm{V}$ Investigators. Stroke prevention using the oral direct thrombin inhibitor ximelagatran in patients with non-valvular atrial fibrillation: Pooled analysis from the SPORTIF III and V studies. Cerebrovasc Dis 2006; 21: 279-293. 